\title{
Parental health literacy and health knowledge, behaviours and outcomes in children: a cross-sectional survey
}

\author{
Elke de Buhr ${ }^{1,2^{*}}$ (D) and Antje Tannen ${ }^{1}$
}

\begin{abstract}
Background: Health literacy $(\mathrm{HL})$ is closely associated with leading health indicators such as engaging in healthy behaviours and experiencing a healthy social environment. Parents represent a critical subgroup among the adult population since they are not only responsible for their own health but also for the health of their children. Previous research suggests that parents with low HL are less likely to meet the preventive and health care needs of their children but there are gaps in the available information and there is not any data available yet for the German context.

Methods: In preparation of an implementation study, a cross-sectional survey was conducted in 28 elementary and secondary schools in Germany. The parent questionnaire was completed by 4217 parents and included the short form of the European Health Literacy Survey Questionnaire (HLS-EU-Q16). The child questionnaire examined children's health knowledge, behaviours and outcomes. For children between 6 and 10 years, a parent reported on behalf of their children $(N=1518)$. Students 11 years and older completed a self-administered questionnaire $(N=$ 2776). Bivariate and multivariate analyses were carried out. Spearman's Rho correlations assess the relationships between household characteristics, parental HL and the health behaviour and outcomes in children.
\end{abstract}

Results: Among the participating parents, $45.8 \%$ showed problematic or inadequate $\mathrm{HL}$. The major determinants of high parental HL were high socio-economic status (SES) $\left(r=.088^{* * *}, 95 \% \mathrm{Cl}[.052, .124]\right)$, living in West Germany $\left(r=.064^{* * *}, 95 \% \mathrm{Cl}[.032, .096]\right)$ and older parental age $\left(r=.057^{* *}, 95 \% \mathrm{Cl}[.024, .090]\right)$. In the multivariate model, only SES remained significant. High parental HL was associated with positive health behaviours in children including healthier nutrition, regular tooth brushing and more physical activity. The relationships between parental HL and smoking, alcohol, sexual activity among children and children's weight were not significant.

Conclusions: The results confirm a relationship between low parental HL, SES and some child health behaviours likely to negatively impact their health and wellbeing including less healthy nutrition and less exercise. Strengthening the health knowledge and competencies of parents may contribute to improved child outcomes particularly in the areas of nutrition, exercise and dental health.

Keywords: Health literacy, Parents, Schoolchildren, Health behaviour, Health outcomes

\footnotetext{
* Correspondence: elke.de-buhr@charite.de; edebuhr@tulane.edu

${ }^{1}$ Charité - Universitätsmedizin Berlin, corporate member of Freie Universität Berlin, Humboldt-Universität zu Berlin, and Berlin Institute of Health and

Nursing Science, Augustenburger Platz 1, D-13353 Berlin, Germany

${ }^{2}$ Tulane University, School of Public Health and Tropical Medicine, 1440 Canal

St., New Orleans, LA 70112, USA
}

(c) The Author(s). 2020 Open Access This article is licensed under a Creative Commons Attribution 4.0 International License, which permits use, sharing, adaptation, distribution and reproduction in any medium or format, as long as you give appropriate credit to the original author(s) and the source, provide a link to the Creative Commons licence, and indicate if changes were made. The images or other third party material in this article are included in the article's Creative Commons licence, unless indicated otherwise in a credit line to the material. If material is not included in the article's Creative Commons licence and your intended use is not permitted by statutory regulation or exceeds the permitted use, you will need to obtain permission directly from the copyright holder. To view a copy of this licence, visit http://creativecommons.org/licenses/by/4.0/. The Creative Commons Public Domain Dedication waiver (http://creativecommons.org/publicdomain/zero/1.0/) applies to the data made available in this article, unless otherwise stated in a credit line to the data. 


\section{Background}

Among the leading health indicators are engaging in healthy behaviours, experiencing a healthy social environment, engaging in responsible sexual behaviour, engaging in substance abuse and using tobacco [1]. Each of these indicators depends to some extent on the information people have about their health and how they use it (knowledge aspects), health-related choices (behavioural factors), the socio-economic and environmental context (environmental, economic and social conditions) as well as the type, quantity and quality of health care people receive (system related factors) [1]. The concept of health literacy is used in various definitions and has been measured with numerous instruments. There is agreement, however, that poorer health literacy is associated with poorer health knowledge, more problematic health behaviours, worse health outcomes, inadequate use of health services and increased health care costs $[2,3]$.

Parents with young children represent a critical subgroup among the general adult population since they are not only responsible for their own life and health but as parents and caregivers they are also responsible for the health and wellbeing of their children. Children are dependent on their parents to prevent and address health problems and they may suffer when their parents' knowledge and skills to fulfil these tasks is insufficient [4, 5]. A study by Sanders et al. [6] describes parental literacy as an important moderator of child health disparities. The research establishes relationships between low parental health literacy and unmet health care needs of children, unnecessary visits to emergency departments, ineffective injury prevention, mistakes in the administration of medication, poor childhood nutrition, inaccurate perception of children's weight (overweight children are perceived as normal weight or underweight) as well as increased risk of exposure to second hand tobacco smoke [6]. A systematic review by DeWalt [7] suggests that poorer parental health literacy is associated with poorer knowledge about health outcomes, behaviours and health services, higher rates of hospitalisations and emergency room visits in children with asthma as well as increased use of non-standardised dosing instruments for administering liquid drugs. A systematic review by Firmino [8] focused on parental oral health literacy and found associations between lower parental oral health literacy and higher rates of dental caries in children as well as poorer oral health-related quality of life [8]. The most recent systematic review by Morrison et al. [5] confirms some of the earlier findings, including the association between parental health literacy and child health but in other areas research findings are inconsistent (e.g., previous findings regarding preventive care, acute care, chronic diseases, the effectiveness of interventions). Drawing on this emerging evidence, multiple recent intervention studies have focused on parental health literacy as part of the intervention, e.g. to treat childhood obesity [9] or to reduce medication errors [10].

A comparison of health literacy survey data from eight European countries shows that adults frequently have difficulties with health-related information such as understanding how political decisions affect health outcomes, judging the credibility of health information in the media or deciding between different treatment options. The prevalence of problematic or inadequate health literacy in the eight countries participating in the survey ranged from 29 to $62 \%$ of the population. In addition, health literacy disparities were observed within each studied population. On average, health literacy was higher for young people with low financial deprivation, for individuals with higher social status and education as well as for women. The level of individual health literacy also was associated with level of physical activity, body mass index (BMI) and alcohol consumption [11].

Although health literacy is receiving increasing attention on the German political stage [12], the available evidence base is still limited. As part of the first round of European health literacy surveys, only one German state (North Rhine-Westphalia) participated. In this German subsample the prevalence of problematic or inadequate health literacy was found to be $46.3 \%$. The survey confirmed relationships between health literacy and smoking as well as between health literacy and physical exercising. However, significant associations could not be established between health literacy and alcohol consumption as well as between health literacy and BMI [11]. The research did not examine the relationship between parental health literacy and child health behaviours or outcomes.

The study presented in this article addresses some of the gaps in the German health literacy research field and may serve to further validate previous findings on the relationship between parental health literacy and child health behaviour and outcomes. It provides the first data to quantify the level of parental health literacy in Germany. In addition, the social determinates of parental health literacy are analysed and vulnerable subgroups of adults and children are identified. We expect that the research findings may contribute to developing and improving health literacy and health information campaigns and other social interventions targeted at parents and their school-aged children.

\section{Methods}

The aim of this study was to better understand parental health literacy in Germany and assess the implications for children's health. Specific objectives were directed at quantifying the level of health literacy among parents of school-aged children including their ability to find, 
understand and appraise health information. The research also aimed to identify health-related skills that are perceived as challenging and document disparities in parental health literacy based on socio-demographic factors. The research finally intended to document the implications of parental health literacy for children's health behaviours and outcomes.

A large cross-sectional survey was carried out in preparation of an implementation study, which placed school nurses at 28 public schools in two federal states in Germany, Brandenburg and Hessen, that did not previously have access to this resource [13-15]. The elementary and secondary schools were selected by the local governments using a purposeful selection process. The 2017 baseline data collection was directed at examining and quantifying relevant health-related conditions. Primary and secondary school systems in Germany differ by state. In Hessen primary schools cover grades 1-4, in Brandenburg they cover grades 1-6. Subsequently, students enter different types of secondary schools and graduate either after grade 10 (vocational track) or after grade 12 (university track). All parents with children in the selected schools and all children 11 years and older attending the schools were invited to participate in the survey. Children and adults received ID numbers to allow the pairing of responses.

The parent questionnaire was completed by 4217 parents. It covered household socio-demographic, health and general wellbeing indicators. It also included the short form of the European Health Literacy Survey Questionnaire (HLS-EU-Q16). Based on a conceptual model of health literacy by Sorensen et al. [16], the original HLSEU-Q47 was developed by the HLS-EU Consortium. The integrative model addresses the competencies of accessing, understanding, appraising and applying healthrelated information in the areas of health promotion, disease prevention and healthcare [16]. The reliability of the scale's 47 self-reported single items was found acceptable for the German version and reached Cronbach's Alpha coefficients between 0.78 and 0.93 [17]. The HLS-EU-Q16 Short Scale, which was applied in this study, was derived using iterative item selection based on Rasch modeling (1parametric dichotomous model) as well as content and face validity criteria [18]. The HLS-EU-Q16 scores were transformed into a unified metric scale with a minimum of 0 and a maximum of 50 points. The minimum of 0 points represents the least possible parental health literacy and the maximum of 50 points represents the highest possible score $[11,17,19]$. To assess socio-economic status (SES) and child health behaviours, standardized tools from large epidemiological surveys were adapted [20-22]. The SES of households was measured using a combination of items: Educational level, vocational training level, current job and income.
The child questionnaire, adapting questionnaire items from previous epidemiological surveys [20-22], covered health knowledge, behaviours and outcomes including nutrition [22], physical activity [21], dental care [21], smoking [20], alcohol use [21], sexual activity [22] as well as BMI [20]. If the child was between 6 (age of school entry) and 10 years, the parent reported on behalf of their children $(N=1518)$. For children 11 years and older, the children completed the questionnaires, which in addition assessed smoking, alcohol use and sexual activity, themselves $(N=2776)$. The minimum age of 11 years for the child questionnaire was selected based on the reading skills and other cognitive competencies needed to complete the form. The questionnaires were self-administered and a pilot test involving a small number of children was completed before the start of data collection to obtain feedback on item comprehension and time needed to complete the form. Completing the questionnaire was voluntary and all data were kept confidential, and an informed consent process was followed. All participants were informed about the objectives of the study and its role in the context of the school nursing intervention. No incentives were offered to parents or children for participation in the research. The parents completed their questionnaires at home, and their children returned these questionnaires in closed envelopes to the school. If parents had more than one child enrolled at the school, they reported on all of their children. The participating children completed their questionnaires in class during a period of time set aside for this task. The completed questionnaires were scanned and entered into an electronic database. The levels of measurements were nominal (sexual activity), ordinal (physical activity, dental care, nutrition, alcohol consumption, smoking, SES) or interval-ratio (BMI, health literacy). Bivariate and multivariate analyses were carried out. Spearman's Rho correlations assess the relationships between parental health literacy, household demographic and socio-economic characteristics, and the health behaviour and outcomes in children.

\section{Results}

\section{Socio-demographic characteristics}

Among the participating parents were 3259 mothers (77.1\%), 675 fathers $(16.0 \%)$ as well as a minority of 44 "other parents" (1.0\%), for example, grandparents. An additional 248 parents (5.9\%) declined to provide information on their relationship to the child. The age of the parents ranged from 19 to 76 years with an average age of 38.1 years withe vast majority of parents between 25 and 55 years old. The 2773 participating children were on average 14.2 years old at the time of data collection with $51.7 \%$ of the children female and $48.3 \%$ male (see Table 1 ). 
Table 1 Demographic Characteristics of Samples

\begin{tabular}{|c|c|}
\hline Average Age of Parents & 38.1 years \\
\hline Average Age of Children & 14.2 years \\
\hline \multirow[t]{4}{*}{ Gender of Parents } & Female: $77.1 \%$ \\
\hline & Male: $16.0 \%$ \\
\hline & Other: $1.0 \%$ \\
\hline & No response: $5.9 \%$ \\
\hline \multirow[t]{2}{*}{ Gender of Children } & Female: $51.7 \%$ \\
\hline & Male: $48.3 \%$ \\
\hline \multirow[t]{6}{*}{ Number of Children } & One child: $24.9 \%$ \\
\hline & Two children: $45.0 \%$ \\
\hline & Three children: $17.5 \%$ \\
\hline & Four children: $6.1 \%$ \\
\hline & Five children: $1.5 \%$ \\
\hline & No response: $5.1 \%$ \\
\hline $\begin{array}{l}\text { Child with Chronic Condition } \\
\text { or Disability }\end{array}$ & $8.4 \%$ \\
\hline \multirow[t]{4}{*}{ Urban/Rural Location } & Above 100,000: $32.7 \%$ \\
\hline & $20,000-100,000: 37.3 \%$ \\
\hline & 10,000-20,000: $21.7 \%$ \\
\hline & Under 10,000: 8.3\% \\
\hline \multirow[t]{2}{*}{ German State } & Brandenburg (East Germany): 54\% \\
\hline & Hessen (West Germany): 46\% \\
\hline N (Parents) & 3980 \\
\hline N (Children) & 2773 \\
\hline
\end{tabular}

Families with two children were most common among the interviewed households. Among the survey respondents, 1052 parents reported having one child (24.9\%), 1901 parents reported two children (45.0\%), 738 parents reported three children (17.5\%), 256 parents reported four children (6.1\%) and 64 parents reported five children (1.5\%). An additional 251 parents declined to provide information on the number of their children (5.1\%). While most parents did not report caring for a child with a health problem, 353 parents $(8.4 \%)$ indicated that their child had a chronic condition or disability (see Table 1).

In terms of socio-economic status, the participants in the survey varied widely. Among the 3189 households that provided the required information on educational level, vocational training, job position, and income, 1047 households (32.8\%) had a high socio-economic status, 1358 households (42.6\%) had a medium socio-economic status and 784 households $(24.6 \%)$ had a low socioeconomic status (see Table 1).

Both urban and rural schools were represented in the sample with $32.7 \%$ of the interviewed children attending school in cities above 100,000 inhabitants, 37.3\% attending school in cities between 20,000 and 100,000 inhabitants and $21.7 \%$ attending school in towns between 10,000 and 20,000 inhabitants. Less than $10 \%$ of the children attended schools in communities with fewer than 10,000 inhabitants. West German households were represented with $54.0 \%$ of the sample and East German households with $46.0 \%$ (see Table 1 ).

The survey population, while not a representative sample and limited to two German states, closely mirrors the population of school-aged children and their parents in Germany with regard to age, sex and social status. In terms of migration status, children with migration background also resembled the German population with $37.4 \%$ of the children in the sample with this characteristic compared to $36 \%$ of the children in the general population [23].

\section{Results for single items of parental health literacy}

Finding "information on how to manage mental health problems like stress or depression" was judged to be "very difficult" by $6.4 \%$ of the reponding parents and "fairly difficult" by $34.8 \%$. Judging "if the information on health risks in the media is reliable" was rated as "very difficult" by $6.2 \%$ of respondents and as "fairly difficult" by $44.0 \%$. Also perceived as difficult was judging "when you may need to get a second opinion from another doctor" with $3.9 \%$ of respondents considering this task to be "very difficult" and $32.5 \%$ "fairly difficult." Similarly, deciding "how you can protect yourself from illness based on information in the media" was experienced as challenging with $3.9 \%$ of the respondents reporting that this task was "very difficult" and $35.8 \%$ reporting it was "fairly difficult" (see Table 2).

On the positive side, following "instructions from your doctor or pharmacist", following "your doctor's or pharmacist's instruction on how to take a prescribed medicine", understanding "health warnings about behaviour such as smoking, low physical activity and drinking too much" and understanding "why you need health screenings" were perceived as "very easy" or "fairly easy" by most of the respondents with less than $10 \%$ of respondents considering these tasks to be "very difficult" or "fairly difficult" (see Table 2).

\section{Prevalence of categories of parental health literacy in the sample}

Among the 3980 parents who provided the required information, $14.9 \%$ had excellent health literacy, $39.3 \%$ had sufficient health literacy, 33.7\% had problematic health literacy, and $12.1 \%$ had inadequate health literacy (see Table 3).

\section{Social determinants of parental health literacy}

The major determinants of high parental health literacy were high socio-economic status (SES) $\left(r=.088^{* * *}, 95 \%\right.$ 
Table 2 HLS-EU-Q16 Health Literacy Matrix Items for Sample

\begin{tabular}{|c|c|c|c|c|c|c|}
\hline Item & On a scale from very easy to very difficult, how easy would you say it is to ... & very difficult & fairly difficult & fairly easy & very easy & $\mathrm{N}$ \\
\hline 1 & find information on treatments of illnesses that concern you? & $1.7 \%$ & $22.2 \%$ & $59.4 \%$ & $16.7 \%$ & 3813 \\
\hline 2 & find out where to get professional help when you are ill? & $1.6 \%$ & $19.0 \%$ & $55.2 \%$ & $24.3 \%$ & 3882 \\
\hline 3 & understand what your doctor says to you? & $1.3 \%$ & $13.8 \%$ & $57.6 \%$ & $27.4 \%$ & 3920 \\
\hline 4 & $\begin{array}{l}\text { understand your doctor's or pharmacist's instruction on how to } \\
\text { take a prescribed medicine? }\end{array}$ & $0.4 \%$ & $3.1 \%$ & $43.6 \%$ & $52.9 \%$ & 3943 \\
\hline 5 & judge when you may need to get a second opinion from another doctor? & $3.9 \%$ & $32.5 \%$ & $45.2 \%$ & $18.4 \%$ & 3887 \\
\hline 6 & use information the doctor gives you to make decisions about your illness? & $1.8 \%$ & $25.3 \%$ & $56.6 \%$ & $16.4 \%$ & 3853 \\
\hline 7 & follow instructions from your doctor or pharmacist? & $0.5 \%$ & $4.3 \%$ & $54.7 \%$ & $40.6 \%$ & 3921 \\
\hline 8 & $\begin{array}{l}\text { find information on how to manage mental health problems like stress } \\
\text { or depression? }\end{array}$ & $6.4 \%$ & $34.8 \%$ & $44.5 \%$ & $14.3 \%$ & 3731 \\
\hline 9 & $\begin{array}{l}\text { understand health warnings about behaviour such as smoking, low } \\
\text { physical activity and drinking too much? }\end{array}$ & $1.2 \%$ & $8.0 \%$ & $44.3 \%$ & $46.4 \%$ & 3849 \\
\hline 10 & understand why you need health screenings? & $0.6 \%$ & $5.1 \%$ & $40.9 \%$ & $53.4 \%$ & 3895 \\
\hline 11 & judge if the information on health risks in the media is reliable? & $6.2 \%$ & $44.0 \%$ & $38.7 \%$ & $11.1 \%$ & 3854 \\
\hline 12 & $\begin{array}{l}\text { decide how you can protect yourself from illness based on information } \\
\text { in the media? }\end{array}$ & $3.9 \%$ & $35.8 \%$ & $46.8 \%$ & $13.5 \%$ & 3845 \\
\hline 13 & find out about activities that are good for your mental well-being? & $2.6 \%$ & $28.9 \%$ & $52.7 \%$ & $15.8 \%$ & 3781 \\
\hline 14 & understand advice on health from family members or friends? & $1.0 \%$ & $10.6 \%$ & $55.5 \%$ & $32.9 \%$ & 3849 \\
\hline 15 & understand information in the media on how to get healthier? & $2.0 \%$ & $19.1 \%$ & $57.6 \%$ & $21.3 \%$ & 3827 \\
\hline 16 & judge which everyday behaviour is related to your health? & $1.5 \%$ & $15.9 \%$ & $56.9 \%$ & $25.8 \%$ & 3845 \\
\hline
\end{tabular}

CI [.052, .124]), living in West Germany $\left(r=.064^{* * * *}, 95 \%\right.$ CI $[.032, .096])$ and older parental age $\left(r=.057^{* * *}, 95 \%\right.$ CI $[.024, .090])$. None of the other socio-demographic variables ("Gender of Parent", "Number of Children", "German Native Speaker", "Child with Chronic Condition or Disability" and "Rural/Urban Location") was a significant determinant of health literacy (see Table 4).

Further analysis revealed moderate inter-correlations between the three significant predictors of parental health literacy: "Socio-Economic Status of Household", "East/West German Location" and "Age of Parent" (see Table 5).

Multivariate analysis points to SES as the most important socio-demographic factor explaining differences in health literacy in the survey population and the only significant predictor in the multiple regression models (see Table 6). After excluding the non-significant predictor

Table 3 Health Literacy Categories for Sample ${ }^{a}$

\begin{tabular}{lll}
\hline & Frequency & Percent \\
\hline Excellent & 592 & 14.9 \\
Sufficient & 1564 & 39.3 \\
Problematic & 1342 & 33.7 \\
Inadequate & 482 & 12.1 \\
Total & 3980 & 100
\end{tabular}

${ }^{a}$ Calculated using the HLS-EU methodology [11] using the following scores: Inadequate health literacy ranging from 0 to 25, problematic health literacy ranging from $>25-33$, sufficient health literacy ranging from $>33-42$ and excellent health literacy ranging from $>42-50$ age (in Model 2) as well as age and location (in Model 3), SES further increases in significance while the explained variance remains equal. However, the models only explain a small percentage of the total variation of health literacy among parents.

The data also indicate that there is a relationship between parental health literacy and self-reported health and wellbeing. Parents with high health literacy reported a better subjective health $\left(\mathrm{r}=.111^{* * * *}, 95 \%\right.$ CI [.079, $.143])$ and quality of life $\left(r=.136^{* * * *}, 95 \%\right.$ CI $\left.[.104, .168]\right)$ (see Table 7).

\section{Parental health literacy and health outcomes in children}

Based on the analysed data, there are strong statistical relationships between parental health literacy and a number of health behaviours in children. Children under 11 years who had parents with high health literacy were eating more vegetables and salad $\left(r=.100^{* * * *}, 95 \% \mathrm{CI}\right.$ $[.047, .153])$ and more fruits $\left(\mathrm{r}=.086^{* *}, 95 \%\right.$ CI [.032, .139]) than other children. These children were more frequently engaged in physical activity $\left(\mathrm{r}=.079^{* * *}, 95 \%\right.$ CI $[.025, .132])$, they were more likely to brush their teeth regularly $\left(\mathrm{r}=.055^{*}, 95 \% \mathrm{CI}[.001, .108]\right)$, and their parents judged them as healthier $\left(\mathrm{r}=.144^{* * *}, 95 \% \mathrm{CI}\right.$ $[.091, .196])$. Relationships between parental health literacy and children's BMI as well as their days missed at school in the last term could not be established (see Table 8). 
Table 4 Demographic Characteristics and Parental Health Literacy

\begin{tabular}{|c|c|c|c|}
\hline Parental Health Literacy and ... & r & $95 \% \mathrm{Cl}$ & $\mathrm{N}$ \\
\hline Gender of Parent ( 1 = male, 2 = female) & .021 & $-.012, .054$ & 3454 \\
\hline Age of Parent (in years) & $.057^{\mathrm{b}}$ & $.024, .09$ & 3388 \\
\hline Number of Children & -.032 & $-.064, .000$ & 3691 \\
\hline German Native Speaker & .022 & $-.01, .054$ & 3612 \\
\hline Child with Chronic Condition or Disability & -.013 & $-.045, .019$ & 3568 \\
\hline Socio-Economic Status of Household (based on parents' education and income) & $.088^{\mathrm{C}}$ & $.052, .124$ & 2844 \\
\hline Rural/Urban Location ( 1 = urban, $5=$ rural) & -.025 & $-.057, .007$ & 3684 \\
\hline East/West German Location ( $0=$ East German, $1=$ West German) & $.064^{\mathrm{c}}$ & $.032, .096$ & 3691 \\
\hline
\end{tabular}

${ }^{a}$ Spearman's Rho Correlation, significant at the .05 level (2-tailed)

${ }^{b}$ Spearman's Rho Correlation, significant at the .01 level (2-tailed)

' Spearman's Rho Correlation, significant at the 001 level (2-tailed)

In the older age group (11+ years), children of parents with better health literacy reported eating more vegetables and salad $(\mathrm{r}=.163 \%$, 95\% CI $[.115, .211])$, and they were drinking fewer sweetened beverages $\left(r=-.096^{* \% * \%}\right.$, 95\% CI $[-.145,-.047])$. They also reported brushing their teeth more regularly $\left(\mathrm{r}=.058^{*}, 95 \% \mathrm{CI}[.008, .107]\right)$. However, there were no significant relationships between parental health literacy and indicators measuring physical activity, alcohol and tobacco consumption, and unprotected sexual activity in this age group. There also were no significant relationships between parental health literacy and children's BMI, child-reported subjective health or their days missed in school in the last term (see Table 9).

\section{Discussion}

Among the participating parents $45.8 \%$ showed a problematic or inadequate health literacy. This percentage is comparable with the results from the first German-wide health literacy survey. In the 2016 survey of the general population, problematic or inadequate health literacy was reported by $41.4 \%$ in the area of coping with disease, $47.7 \%$ in the area of disease prevention, and $60.3 \%$ in the area of health promotion [17]. The health literacy scale's single items indicated that media literacy was a particular problem for many parents ("judge information on health risks in the media", "protect yourself from illness based on information in the media"), judgement calls were also difficult and information on mental health and treatments were perceived as insufficient. On the other hand, understanding health professionals and following basic instructions were regarded as comparably easy. This may point to information overload and online misinformation as possible factors contributing to problems with accessing and using the available health information. In the German wide health literacy survey, difficulties with media information were reported by $49.3 \%$ of the participants [17].

SES was the best predictor of health literacy in parents and the only socio-demographic variable that remained significant in the multivariate model. The correlations between parental health literacy and the subjective health of parents as well as parental health literacy and the quality of life of parents confirm that individuals with higher health literacy (and higher SES) also tend to have better subjective health and quality of life. While the correlation between SES and health literacy are in line with previous empirical research [11] and with theoretical models of health literacy $[12,16]$, the explanatory power of SES as a predictor of health literacy was limited. Besides personal skills and abilities, including the knowledge, motivation and competences to deal with health information, the demands of the needed evidence

Table 5 Correlations between Age of Parent, Socio-Economic Status and East/West German Location

\begin{tabular}{lllll}
\hline & & East/West German Location & Age of Parent & SES of Household \\
\hline East/West German Location & Correlation Coefficient & 1 & $.429^{c}$ & 3621 \\
& $\mathbf{N}$ & 3021 & 3021 & 3021 \\
Age of Parent & Correlation Coefficient & $.429^{c}$ & 1 & $.372^{c}$ \\
& $\mathbf{N}$ & 3021 & 3021 & 3021 \\
SES of Household & Correlation Coefficient & $.362^{c}$ & $.372^{c}$ & 1 \\
& $\mathbf{N}$ & 3021 & 3021 & 3021 \\
\hline
\end{tabular}

\footnotetext{
a Spearman's Rho Correlation, significant at the .05 level (2-tailed)

${ }^{b}$ Spearman's Rho Correlation, significant at the .01 level (2-tailed)

' Spearman's Rho Correlation, significant at the 001 level (2-tailed)
} 
Table 6 Multiple Regression Model Predicting Variation in Parental Health Literacy

\begin{tabular}{llll}
\hline Independent Variables $^{\mathbf{a}}$ & \multicolumn{3}{l}{$\begin{array}{l}\text { Dependent Variable }- \text { Parental Health } \\
\text { Literacy }\end{array}$} \\
\cline { 2 - 4 } & Model 1 & Model 2 & Model 3 \\
\hline Intercept & $33.495^{* * *}$ & $78.650^{* * *}$ & $78.660^{* * *}$ \\
East/West German Location & .643 & .769 & - \\
Age of Parent & .322 & - & - \\
SES of Household & $4.327^{* * *}$ & $4.660^{* * *}$ & $5.284^{* * *}$ \\
Model Fit & & & \\
\multicolumn{1}{c}{$\mathbf{R}^{\mathbf{2}}$} & .010 & .010 & .010 \\
$\mathbf{A d j u s t e d} \mathbf{R}^{\mathbf{2}} \mathbf{b}$ & .009 & .009 & .009 \\
$\mathbf{F}$ & $9.236^{* * *}$ & $14.254^{* * *}$ & $27.921^{* * *}$ \\
$\mathbf{N}$ & 2682 & 2843 & 2843 \\
\hline
\end{tabular}

${ }^{*} p<.05,{ }^{* *} p<.01,{ }^{* * *} p<.001$

a Entries are regression coefficients

b The Adjusted $R^{2}$ adjusts for number of variables relative to number of cases

as well as the perceived and actual complexities of the health system also exert an influence when explaining self-perceived health literacy [16].

Confirming earlier studies, the research showed a relationship between the health and wellbeing of children and the health literacy of their parents. High parental health literacy was associated with positive health behaviours in children including higher consumption of fruits and vegetables, less consumption of sweetened beverages, regular tooth brushing as well as more frequent physical activity. The relationships between parental health literacy and children's smoking, children's alcohol consumption and risky sexual activity among children (for children 11 years and older) as well as children's BMI (both age groups), however, were not significant and other factors have to be considered.

The research provides the first quantitative data on the relationship between parental health literacy and the health behaviours of school-aged children in Germany. Among the strengths of the study are the large sample and the diversity of the participating schools, which approximate the complexity of the German educational landscape. The study also benefits from access to and the ability to compare responses from both parents and their children. Potential limitations include the non-probability

Table 7 Parental Health Literacy and Subjective Health and Life Satisfaction

\begin{tabular}{llll}
\hline Parental Health Literacy and $\ldots$ & $r$ & $95 \% \mathrm{Cl}$ & $\mathrm{N}$ \\
\hline Subjective Health of Parents & $.111^{\mathrm{c}}$ & $.079, .143$ & 3468 \\
Life Satisfaction of Parents & $.136^{c}$ & $.104, .168$ & 3435 \\
\hline
\end{tabular}

a Spearman's Rho Correlation, significant at the .05 level (2-tailed)

${ }^{b}$ Spearman's Rho Correlation, significant at the .01 level (2-tailed)

' Spearman's Rho Correlation, significant at the 001 level (2-tailed)
Table 8 Parental Health Literacy and Adult-Reported Health Behaviours and Outcomes for Children 6 to 11 Years

\begin{tabular}{llll}
\hline Parental Health Literacy and ... & $r$ & $95 \% \mathrm{Cl}$ & $\mathrm{N}$ \\
\hline Children's Regular Physical Activity & $.079^{\mathrm{b}}$ & $.025, .132$ & 1299 \\
Children's Regular Tooth Brushing & $.055^{\mathrm{a}}$ & $.001, .108$ & 1306 \\
Children's Regular Visit to Dentist & .020 & $-.034, .074$ & 1294 \\
Children's Healthy Nutrition - Consumption of... & & \\
Fruit & $.086^{\mathrm{b}}$ & $.032, .139$ & 1310 \\
Vegetables, Salad & $.100^{\mathrm{c}}$ & $.047, .153$ & 1310 \\
Chocolate and other Sweets & .037 & $-.017, .090$ & 1310 \\
Potato Chips, Fries and Similar & -.047 & $-.100, .007$ & 1310 \\
Cola and Other Sweetened Beverages & .009 & $-.045, .063$ & 1310 \\
Children's BMl & .002 & $-.057, .061$ & 1086 \\
Children's Subjective Health & $.144^{\mathrm{c}}$ & $.091, .196$ & 1298 \\
Children's Number of Days Missed at School & -.054 & $-.111, .004$ & 1131
\end{tabular}

a Spearman's Rho Correlation, significant at the .05 level (2-tailed)

${ }^{b}$ Spearman's Rho Correlation, significant at the 01 level (2-tailed)

'Spearman's Rho Correlation, significant at the .001 level (2-tailed)

selection of the schools, a regional distribution that does not cover all federal states and some survey/item non-response caused by the research's voluntary nature. In addition, both adults and children may have experienced challenges with responding to the survey questions. Self-reporting on health literacy and other health-related topics is vulnerable to social desirability bias, perhaps even more so in the context of a school nursing intervention. It is also conceivable that the response behaviour of the participants was influenced by their opinion of the school nursing intervention.

Table 9 Parental Health Literacy and Child-Reported Health Behaviours and Outcomes for Children 11 Years and Older

\begin{tabular}{llll}
\hline Parental Health Literacy and ... & $r$ & $95 \% \mathrm{Cl}$ & $\mathrm{N}$ \\
\hline Children's Regular Physical Activity & .001 & $-.06, .062$ & 1001 \\
Children's Regular Tooth Brushing & $.058^{\mathrm{a}}$ & $.008, .107$ & 1526 \\
Children's Regular Visit to Dentist & .007 & $-.043, .057$ & 1506 \\
Children's Healthy Nutrition - Consumption of... & & \\
$\quad$ Fruit & .037 & $-.012, .086$ & 1551 \\
Vegetables, Salad & $.163^{\mathrm{a}}$ & $.115, .211$ & 1551 \\
Chocolate and other Sweets & -.007 & $-.056, .042$ & 1551 \\
Potato Chips, Fries and Similar & -.040 & $-.089, .009$ & 1551 \\
Cola and Other Sweetened Beverages & $-.096^{\mathrm{c}}$ & $-.145,-.047$ & 1551 \\
Children's Alcohol Consumption & .005 & $-.046, .056$ & 1476 \\
Children's Tobacco Consumption & -.013 & $-.063, .037$ & 1498 \\
Children's Sexual Activity without & -.020 & $-.072, .032$ & 1408 \\
Protection & & & \\
\hline
\end{tabular}

${ }^{a}$ Spearman's Rho Correlation, significant at the .05 level (2-tailed)

${ }^{b}$ Spearman's Rho Correlation, significant at the .01 level (2-tailed)

' Spearman's Rho Correlation, significant at the .001 level (2-tailed) 


\section{Conclusions}

The results confirm a relationship between low parental health literacy, SES and some child health behaviours likely to negatively impact their health and wellbeing including less healthy nutrition and less exercise. Hence these factors should be monitored as vulnerable families may require additional support to improve their health knowledge, access the available health information, navigate the health care system and with health-related decisions. Strengthening the health knowledge and competencies of parents may contribute to improved child outcomes particularly in the areas of nutrition, exercise and dental health.

While the sample was not representative of the entire country, the collected data provide a first window into the relationship between parental health literacy and child health in Germany. Additional research is needed to further explore the relative contribution of parental health literacy to children's health behaviours and outcomes.

\section{Abbreviations}

BMI: Body Mass Index; HL: Health Literacy; HLS-EU: Health Literacy Survey European Union; SES: Socio-Economic Status;

SPLASH: Schulgesundheitspflege an allgemeinbildenden Schulen/School Nursing at General Schools; US: United States of America

\section{Acknowledgements}

The authors would like to thank SPLASH I / I project director Prof. Dr Michael Ewers as well as Yvonne Adam and Jennifer Ebert for their contributions to data collection, analysis, and their thoughtful discussions and valuable feedback.

\section{Authors' contributions}

Analysed the data: EDB. Wrote the paper: EDB, AT. Both authors read and approved the final manuscript.

\section{Authors' information}

Dr. Elke de Buhr, PhD, MS, is a senior researcher at the Charité Universitätsmedizin Berlin, Institute of Health and Nursing Science, and an adjunct assistant professor at Tulane University's School of Public Health and Tropical Medicine in New Orleans, USA.

Dr. Antje Tannen, MPH, is a nursing scientist, health scientist and senior researcher at the Charité - Universitätsmedizin Berlin, Institute of Health and Nursing Science.

\section{Funding}

The project was commissioned by the HAGE (Hessische Arbeitsgemeinschaft für Gesundheitsförderung). The donor had no role in the analysis or interpretation of the results.

\section{Availability of data and materials}

Due to data protection regulations, the data of the participating parents and children are confidential and cannot be shared for further analyses.

\section{Ethics approval and consent to participate}

Ethics approval was obtained from the ethics committee of the German Society of Nursing Science on July 19, 2017 (No. 16-025). Participation in the research was voluntary and confidential. All survey participants were provided with written documentation summarizing the purpose of the research, the methodology and their rights as participants. Informed consent was required for both adult and child surveys. A consent form was signed by the parents to document approval. Children 14 years and older also signed a consent form. Younger children provided verbal assent. No child was interviewed without the consent of a parent.

\section{Consent for publication}

Not applicable.

\section{Competing interests}

The authors declare that they have no competing interests.

Received: 7 March 2019 Accepted: 10 May 2020

Published online: 13 July 2020

\section{References}

1. Institute of Medicine (US) Committee on Leading Health Indicators for Healthy People 2020. Leading Health Indicators for Healthy People 2020: Letter Report. Washington (DC): National Academies Press (US); 2011.

2. Yin HS, Johnson M, Mendelsohn AL, Abrams MA, Sanders LM, Dreyer BP. The health literacy of parents in the United States: a nationally representative study. Pediatrics. 2009;124(Suppl 3):S289-98.

3. Berkman ND, Sheridan SL, Donahue KE, Halpern DJ, Crotty K. Low health literacy and health outcomes: an updated systematic review. Ann Intern Med. 2011;155(2):97-107.

4. Johnston R, Fowler C, Wilson V, Kelly M. Opportunities for nurses to increase parental health literacy: a discussion paper. Issues in Comprehensive Pediatric Nursing. 2015;38(4):266-81.

5. Morrison AK, Glick A, Yin S. Health literacy: implications for child health. Pediatr Rev. 2019;40(6):263-75.

6. Sanders LM, Shaw JS, Guez G, Baur C, Rudd R. Health literacy and child health promotion: implications for research, clinical care, and public policy. Paediatrics. 2009;124(3):S306-14.

7. DeWalt DA, Hink A. Health literacy and child health outcomes: a systematic review of the literature. Pediatrics. 2009;124(Suppl 3):S265-74.

8. Firmino RT, Ferreira FM, Martins CC, Granville-Garcia AF, Fraiz FC, Paiva SM. Is parental oral health literacy a predictor of children's oral health outcomes? Systematic review of the literature. J Am Dent Assoc. 2017;148(8):604-13.

9. Zoellner JM, Hill J, You W, Brock D, Frisard M, Alexander R, Silva F, Price B, Marshall R, Estabrooks PA. The influence of parental health literacy status on reach, attendance, retention, and outcomes in a family-based childhood obesity treatment program, Virginia, 2013-2015. Prev Chronic Dis. 2017;14:E87.

10. Yin HS, Parker RM, Sanders LM, Dreyer BP, Mendelsohn AL, Bailey S, Patel DA, Jimenez JJ, Kim KA, Jacobson K, Hedlund L, Smith MC, Maness Harris L, McFadden T, Wolf MS. Liquid Medication Errors and Dosing Tools: A Randomized Controlled Experiment. Pediatrics. 2016;138(4):117. https://www. uni-bielefeld.de/gesundhw/ag6/downloads/Ergebnisbericht_HLS-GER.pdf.

11. HLS-EU Consortium. Comparative report of Health Literacy in eight EU member states. The European Health Literacy Survey HLS-EU. 2012. Online publication: http://www.health-literacy.eu Accessed 10 Dec 2018.

12. Schaeffer D, Hurrelmann K, Bauer U, Kolpatzik K. Nationaler Aktionsplan Gesundheitskompetenz. KomPart: Die Gesundheitskompetenz stärken. Berlin; 2018

13. Tannen A, Adam Y, Ebert J, Ewers M. Schulgesundheitsfachkräfte: Evaluation eines Modellprojekts. Pflegezeitschrift. 2017;70(9):53-5.

14. Tannen A, Ebert J, Adam Y, Ewers M. Schulgesundheitspflege - ein neues Aufgabengebiet für die Pflege. Heilberufe Das Pflegemagazin. 2017a;69(9): 59-61.

15. Tannen A, Ebert J, Adam Y. Schuleigene Pflegekräfte an allgemeinbildenden Schulen. Kinderkrankenschwester. 2018;37(5):150-4.

16. Sørensen K, Van den Broucke S, Fullam J, Doyle G, Pelikan J, Slonska Z, Brand H, European CHLP. Health literacy and public health: a systematic review and integration of definitions and models. BMC Public Health. 2012; 12:80.

17. Schaeffer D, Vogt D, Berens EM, Hurrelmann L. Gesundheitskompetenz der Bevölkerung in Deutschland - Ergebnisbericht. Bielefeld: Universität Bielefeld; 2016

18. Pelikan JM, Röthlin F, Ganahl K. Measuring comprehensive health literacy in general populations: validation of instrument, indices and scales of the HLSEU study. Ludwig Boltzmann Institute Health Promotion Research. Vienna: 6th Annual Health Literacy Research Conference, November 3-4; 2014.

19. Röthlin F, Pelikan JM, Ganahl K. Die Gesundheitskompetenz der 15- jährigen Jugendlichen in Österreich. Abschlussbericht der österreichischen Gesundheitskompetenz Jugendstudie im Auftrag des Hauptverbands der österreichischen Sozialversicherungsträger (HVSV). 2013.

20. RKI (Robert Koch-Institut) Studie zur Gesundheit von Kindern und Jugendlichen in Deutschland: Ergebnisse der ersten Folgebefragung (KIGGS 
Welle 1). Bundesgesundheitsblatt - Gesundheitsforschung -

Gesundheitsschutz. 2014;57(4).

21. Moor I, Richter M, Ravens-Sieberer U, Ottova-Jordan V, Elgar FJ, Pförtner TK.

Trends in social inequalities in adolescent health complaints from 1994-

2010 in Europe, North America and Israel: the HBSC study. Eur J Pub Health. 2015;25(2):57-60

22. Lange M, Kamtsiuris P, Lange C, Schaffrath Rosario A, Stolzenberg H, Lampert T. Messung soziodemographischer Merkmale im Kinder- und Jugendgesundheitssurvey (KiGGS) und ihre Bedeutung am Beispiel der Einschätzung des allgemeinen Gesundheitszustands.

Bundesgesundheitsblatt Gesundheitsforschung Gesundheitsschutz. 2007; 50(5-6):578-89.

23. Bundeszentrale für politische Bildung (bpb) Datenreport 2018 - Ein Sozialbericht für die Bundesrepublik Deutschland. Statistisches Bundesamt (Destatis), Wissenschaftszentrum Berlin für Sozialforschung (WZB). Bonn; 2018

\section{Publisher's Note}

Springer Nature remains neutral with regard to jurisdictional claims in published maps and institutional affiliations.

Ready to submit your research? Choose BMC and benefit from:

- fast, convenient online submission

- thorough peer review by experienced researchers in your field

- rapid publication on acceptance

- support for research data, including large and complex data types

- gold Open Access which fosters wider collaboration and increased citations

- maximum visibility for your research: over $100 \mathrm{M}$ website views per year

At BMC, research is always in progress.

Learn more biomedcentral.com/submissions 